\title{
How Geogames Can Support Geographical Education?
}

\author{
Rukiye ADANALI 1 \\ Muğla Sıtkı Koçman University, Muğla, TURKEY
}

1 Dr. Muğla Sıtkı Koçman University, Faculty of Education, Department of Social Studies Education, Muğla, TURKEY. rukiyeadanali [at] mu.edu.tr. ORCID: 0000-0002-7948-4751

\begin{abstract}
Knowledge of geography is one of the main elements in solving problems such as urbanization, socio-economic inequalities, disease, migration, natural disasters. It is also seen that importance is given to the acquisition of geographical skills in educational programs. The spatial thinking skill that provides geospatial information is a geographic skill needed in the analysis and interpretation of place. Geographical inquiry skill focuses on solving a problem in line with certain research processes. Geographic information systems are the basic spatial technology used in the development of spatial thinking and geographic inquiry skills. These three elements are effective tools for solving real-life problems and have become even more important today with the development of location-based mobile applications. It is believed that Geogames from digital games can be an effective new teaching technology in learning these elements within the framework of motivational sources and learning needs in the learning environments of generation Z, which was born into digital technology. Geogames are mobile, location-based, and location- aware games for devices such as smartphones and tablets. In the literature, some types of geogame can also be classified as serious game or pervasive game. Geogame is separated from these games by its focus on solving a spatial problem with its stakeholders, mainly using GIS technology, and is closely related to the science of geography. This review is intended to question how Geogames can support geographical education. For this purpose, Youplaceit! Geocaching on the Moon, Neocartographer, Ingress, OriGami, SimCity, Project Lily Pad, Minecraft-Urban Planning, and FindeVielfalt Simulation geogame applications have been studied in terms of current learning outcomes and features. According to the results, these games can be used in the teaching of physical and human geography topics such as environmental education, urban planning, space geography, tourism geography; can be effective in teaching map skills, spatial thinking, and geographic inquiry skills; can increase collaborative work and motivation. It has been determined that there is a need for research that will provide concrete data in this new academic discipline, and some research questions have been put forward for geography educators and researchers.
\end{abstract}

\section{Keywords}

Geogame, Geographical Inquiry Skill, Spatial Thinking Skill, Map Skills, Location Based Mobile Games 
Since the past, geography has been one of the essential tools in the solution of problems such as urbanization, socio-economic inequalities, disease, migration, extinction of plants and animals, desertification, natural disasters, limited resources, land use, ethnic conflicts; from local to a global scale, in the cause, distribution, classification, an association of events and implementation of the solution. Therefore, it is seen that every day more and more importance is given in education programs to attainment basic map skills of geography, spatial perception, and geographical inquiry from an early age (Artvinli \& Kaya, 2010). Artvinli \& Kaya (2010), noted that the skills and knowledge of the field that can be acquired in geography education can contribute to the effective solution of regional and thematic problems such as socio-spatial inequalities, disasters, sustainable development, environmental problems. Therefore, in the active participation of students in solving these problems, they must first acquire 8 basic geographic skills and, among them, spatial thinking skills with a wide range of cognitive thinking skills. These skills are: Geographical observation, working in the field, geographical inquiry, time perception, change and continuity perception, map skills, table, chart and diagram preparation and interpretation, and using evidence (Ministry of National Education [MoNE], 2018). In 1994, the American National Geography standards defined the skills that students should have at the end of fourth, eighth, and twelfth grades as the ability to ask geographical questions, acquire geographical information, organize geographical information, analyze geographical Information, and respond to geographical questions (GESP, 1994 as cited in Ünlü \& Yıldırım, 2017).

Geographical inquiry skills cover all of these skills and enable students to actively participate by producing projects in the process of solving human and physical geography problems of a regional-global nature. In educational processes where geographical questioning remains superficial, students perceive geography as a boring, rote-based course that memorizes mountain, river, and city names. (Artvinli, 2020, p. 113). "Geographic inquiry involves an individual or collaborative process and research that begins with geographical questions, develops activities and proceeds through the collection, evaluation, interpretation, and analysis of results" (Artvinli 2020, p. 92). Problems of spreading activities over a long period of time, lack of access to different venues, and lack of materials to attainment geographical inquiry exist in almost every country (Artvinli, 2020, p. 93). In various studies, it is said that although geographical inquiry skills are included in educational programs, the research skills that form the infrastructure of this skill at the secondary school level and geographical inquiry skills at the high school level could not be put enough into practice (Artvinli \& Kaya, 2010; Artvinli 2020).

The spatial thinking skill to acquire geospatial knowledge, which is included in the geographic skills; it is a geographical skill that helps to analyze and interpret every living space, primarily in our immediate surroundings (Ünlü \& Yıldırım, 2017). Spatial thinking, which is among the forms of thinking such as oral, logical, mathematical thinking, is a sum of cognitive skills. The key to spatial thinking is a constructive mix of place concepts, representation tools, and reasoning processes (National Research Council [NRC] 2006, p.12). By using Geography Information Systems (GIS), students can deal with problem situations such as mapping and 
analyzing patterns of an invasive weed species, mapping crime patterns in a city school district, mapping seasonal water quality change in a local river, or can deal with problems like selecting potential areas for a parking spot in a wildlife reserve (NRC, 2006, p.179). From this point of view, the map skills used to read and understand maps, which are the most basic communication tool of geography, are the basis of spatial thinking skills. In addition, geospatial technologies such as GIS, which are used in the analysis of space, are an important part of spatial thinking, geographic inquiry, and consequently geography teaching (NRC 2006, p. 217; Ünlü \& Yıldırım, 2017). Individuals who have developed spatial thinking skills can determine the cause and consequences of geographical events occurring in their environment, their routes, and the distribution of existing objects (Ünlü \& Yıldırım, 2017).

There is broad agreement on the interdisciplinary power of spatial thinking; spatial literacy is by its very nature an interdisciplinary competence, from STEM to social sciences and the arts. It is central to the primary and secondary curriculum in many countries and not only has the potential for individual success but also feeds into the importance of the use of spatial knowledge in society. Spatial literacy is taught mainly in paper and pen tasks. This is also due to the lack of appropriate educational geogames that offer ready-to-use solutions for teachers (Bartoschek, Schwering, Li, Münzer, \& Carlos, 2018). Students' understanding of the environment and environment in which they live is contributed by developing the best geographical inquiry skills (Artvinli 2020). In this context, educators are in search of a new approach to gaining geographic inquiry and map-based spatial skills to students. Different learning and perception situations of the generation born into the digital age have been included in this process with both positive and compelling features today.

When designing learning environments, students' readiness levels, habits, and needs are taken into account. In this context, the $\mathrm{Z}$ generation born into digital technology and familiar with this technology; in other words, the sources of motivation of digital natives in their learning environments are quite different from the digital immigrants who were later introduced to this new technology (Bilgiç, Duman, \& Seferoğlu, 2011; Cömert, 2020; Prensky, 2001). Although it is not always possible to move real-life experiences into learning environments, the most reliable and easy way to do this is through games (Polat \& Varol, 2012). Games are also used for different purposes such as measurement and evaluation, skill acquisition, development of existing abilities, reinforcement (Hays \& Singer, 1989 as cited in Cömert, 2020). Digital games, which are of great interest to Generation Z today, can be a good way to give students geographical skills and map-based spatial thinking skills.

It is thought that the learning needs of generation $\mathrm{Z}$ can be met in a way that appeals to them through these games, which are played on different platforms from mobile phones to tablets and desktop computers, and even have their own social media platforms; so their current contributions to geographic inquiry and spatial thinking skills should be determined. Indeed considering the studies such as virtual reality games VR-ENGAGE (Virvou, Katsionis, \& Manos, 2005), Quest Atlantis applications (Barab, Thomas, Dodge, Carteaux, \& Tüzün, 2005), and the application 
of the Global Village game which about the world continents and countries at the primary school level (Tüzün, Yılmaz-Soylu, Karakuş, Inal, \& Kızılkaya, 2009); it was concluded that computer games in geography education increase students' motivation to learn, improve their geographical knowledge and make students active. Seidel, Bettinger, \& Budke (2020), noting that $93 \%$ of young people between the ages of 10 and 18 in Germany play video games every day; according to them, video games can help create and develop people's understanding of geopolitics in political geography and especially popular geopolitics subjects. Seidel et al. (2020)'s work provides insight into the potential and challenges of digital strategy games for politics education in geography classes in secondary schools and teacher training in universities.

Serious games, one of the types of digital games, connects entertainment and learning. Moreover, geogames, which refer to real places, can be perceived as information transfer, inquiry-based learning, and as an effective form of entertainment. Thus, geogames in learning environments belong to the conceptual realm of digital game-based learning (Prensky, 2001). As of July 2016, 45 million users have played Pokémon Go simultaneously worldwide (Freese, 2016), and so the potential of geogames was seen (Schaal, Otto, Schaal \& Lude, 2018). In the literature research conducted for this study in which the contribution of geogames to geography knowledge, spatial thinking, and geographic skills is questioned, it has been understood that there is no complete consensus on the classification of digital games; especially in the context of frequently encountered digital games, locationbased mobile games, pervasive games, and serious games concepts. Therefore, in order to understand geogame's place and background in digital games, it is necessary to simply address the classification of digital games.

Digital games are entertainment and leisure activity software (Frasca, 2001) where one or more players can play together on electronic platforms such as computers and game consoles. Digital and electronic games appear in different forms and on many different computer platforms: games for personal computers or TV-connected game consoles such as Sony Playstation or Microsoft XBox; Handheld gaming devices such as the Nintendo Game Boy Advance or dedicated handhelds that only play one game; Games for PDAs or cell phones; games for arcades or amusement parks. Digital and electronic games can be designed for a single player, a small group of players, or a large community (Sallen \& Zimmerman, 2003, chp.8, p.1). Sallen \& Zimmerman (2003), to be simple, describes all these game forms as digital games. It is not easy to evaluate games in a single classification, as the increase in opportunities offered by digital media leads to the release of more complex games. As a matter of fact, today a digital war game can simultaneously incorporate social game features through action, strategy, role-playing, simulation and social media interaction (Cömert, 2020).

The three important concepts that have emerged in digital game classifications in recent years are location-based mobile games, pervasive games, and serious games. Although entertainment and leisure activities are at the forefront of digital games, the fondness of children and young people for digital games (Seidel et al., 2020) encouraged educators to seek innovative learning strategies that blend entertainment with education. As a result of the understanding that game 
technology can provide an entertainment framework in which serious content can be embedded, serious games have emerged as a separate genre in the world of interactive media (Ratan \& Ritterfeld, 2009).

A serious game focuses directly on education and facilitates learning experiences. In the design of serious games, there must be one or more experts on the subject to be trained on; experts continue to advise even after the game has been designed. The pedagogical approach used in serious games is similar to problem-based learning, where the structure and narrative of the game provide instant motivation to follow the purpose of learning and the necessary knowledge. There should also be meaningful problems that need to be solved in order to learn the content (Barbosa, Pereira, Dias, \& Silva, 2014). Nguyen (2016) noted that any digital game that will provide certain benefits for the user, even if it is not specifically designed as a serious game, can also actually be described as a serious game. Thus, Ratan and Ritterfeld (2009) stated that the simplest solution to the problem of determining a precise definition of serious games is to treat every game called serious games as a serious game.

While serious games from digital games focus on education, the ones where the game's connection with technology comes to the fore, as well as breaking down the spatial, temporal, and social boundaries of traditional games are defined as pervasive games (Stenros, Montola, \& Mäyrä, 2007). Pervasive games, where the fictional world in which the game takes place and the physical world are intermingled, have been associated with augmented and mixed reality games, liveaction role-playing, emotional games, virtual reality games, mobile games, alternative reality games, cross-media games, and augmented desktop games. Games such as Pokémon Go, Négone, the Killer, The Beast, Shelby Logan's Run, BotFighters, Pac-Manhattan, Uncle Roy All Around you, and The Amazing Race are common examples of games (Wikipedia, pervasive game, 20 January 2021)

Location-based mobile games (LBMGs) are persaive LBMGs by nature, as they can be played throughout the city and challenge the use of common public places, changing their roles and, ultimately, their appearance (Avouris \& Yiannoutsou, 2012; Spallazzo \& Mariani, 2018). Pokémon Go is an example of common LBMG as it can be played anywhere. But in a real sense, it can only be said that global games are pervasive games (Spallazzo \& Mariani, 2018). Although location-based games are divided into 3 groups as mobile games, location-aware games, and spatial-aware games, each game with spatial awareness is also a location-aware game, and in turn, any location-aware game is also a mobile game (Nicklas, Pfisterer, \& Mitschang, 2001).

Looking at the typology of LBMGs in the literature, Flintham et al. (2003) and Montola (2011) call LBMGs mixed-reality games due to the fact that they are played with digital content that overlapping between reality between the digital and physical worlds; de Souza e Silva ve Delacruz (2006) refer to them as hybrid-reality games, and Squire et al. (2007) with Jacob et al. (2012), called augmented reality games (as cited in Spallazzo \& Mariani, 2018). A typical example of such games is the group of games called "City games" or "street games"; they are multiplayer games played on city streets and in established urban environments (Avouris \& 
Yiannoutsou, 2012). While most of these games were originally designed for players to have fun, in many cases learning is an implicit result and is often a clear aim of designers. Some activities inherent in these games, such as moving to a specific location, studying artifacts, taking photos, and recording video or audio, take place in the physical place (Avouris \& Yiannoutsou, 2012).

Until recently, location-based technologies consisted of various applications or navigation software. Currently, smartphones meet GPS and mobile internet networks; social networks, mobile games, navigation tools, etc. almost every user has a location-based application on their smartphone (Tokgöz, 2017). LBMGs are new gaming experiences with versatile and rich cultural elements at the intersection of mobile devices, location data, urban culture, wireless communication, fiction and narrative. The difference between LBMG's and other mobile games is that in order to play, it is necessary to roam and move around the physical place. The difference between games played in physical place is necessarily the need to use a mobile device as an interface (Tokgöz, 2017). LBMG's are usually multiplayer. The player interacts with geographically positioned virtual items in physical place. Interaction and collaboration between players are characteristic of the game. Geocaching, a mobile game based on GPS and an outdoor treasure hunt; location-aware social strategy game Gowar; location-based multiplayer game Mogi and Alien Revolt, Botfighters, and Zombies Run! are major examples of LBMG (Tokgöz, 2017).

In this study, geogames are mentioned under digital games. In the literature, "Geogames", "Location-based games" and "Geospatial games" are used interchangeably the expressions (Andrade, Poplin, \& Sena, 2020; Poplin, Kerkhove, Reasoner, Roy, \& Brown, 2017; Schlieder, Kiefer, \& Matyas, 2006). Geogames are games that use real-world spatial information that constitutes Geographic content or visualize a real spatial context that can be transmitted through geographic information technology such as Geographic Information Systems (GIS). Schlieder and colleagues (Schlieder, et al., 2006) are the first researchers to introduce the concept of 'geogames' in the literatüre (Andrade et al., 2020).

Geogames is an emerging field of research that focuses on the value of place and explores different geospatial visualizations and their use in a variety of applications (de Andrade, 2019 as cited in Andrade et al., 2020). As an academic discipline, Geogames covers a scientific perspective focused on the phenomenon of urbanization, which explores the capacity and activism of fictional representation of reality in digital interaction. Some very successful commercial games, such as Minecraft, Ingress, Pokémon GO, Harry Potter Wizards United, and The Game Of Thrones, have taken places at the center of the game as a geospatial component in map forms, visualizations of geographical contexts, and playability (Andrade et al., 2020; Yamu, Poplin, Devisch, De Roo, 2017).

The characteristic properties of geogames can be sorted as follows (Andrade et. al., 2020; Yamu, Poplin, Devisch, \& De Roo, 2017):

1. Based on a specific location where the game environment and spatial components can be represented and visualized;

2. Focusing on solving a spatial problem with the citizens of the chosen place; 
3. Inclusion of rules and elements of pleasure to attract citizens to continue playing and returning to the game;

4. Ensuring citizens' participation in the urban planning process

Geogames are mobile, location-based, and location aware games for devices such as smartphones and tablets. They offer a variety of possibilities for environmental education as they can be played outdoors (Schaal, et. al., 2018). Although many examples of geogames for developing disaster resistance, sustainable environmental management, urban design, urbanization problems, map-based spatial skills are in the literature especially for the areas where people are native; due to the technical equipment and expertise it requires (except for commercial ones), geogame is a field of instructional technology still developing. A first-of-itskind book about Geogames and Geoplay (Ahlqvist \& Schlieder, 2018) was published in 2018 with a collection of different perspectives on geographic games (Andrade et al., 2020). While Nebel, Schneider, \& Rey (2016) stated that geogame is still limited studies on the use of existing training practices in the game Minecraft; Lefebvre (1970) with Mather \& Robinson (2016), stated that this lack was even greater in architecture, urban planning, or in the field of geography (as cited in Andrade et al., 2020). Carbonell Carrera, Saorín, \& Hess Medler (2018) stated that playing Pokemon GO can be used as a tool to improve spatial orientation skills, but there is not enough proven data in the literature of the field. Baker et al. (2015) report that the benefits of geo-technologies in learning environments are frequently mentioned in the literature. But according to them, due to the inadequacy of well-designed, systematic, multidisciplinary, and repeatable studies on this subject, the knowledge of the educational potential of geo-technologies could not be given in a real concrete way.

As can be seen from its definition, geogames seem to be very compatible with the science of geography, which, on a local, regional, and global scale, deals with the solution of many problems such as urbanization, migration, global warming, disasters, border conflicts, and environmental problems. At the same time, when its connections with GIS technology and spatial thinking ability are also considered, the question of how this new instructional technology, which is still developing, can be evaluated in geography education, comes to mind. As a matter of fact, geogame applications were not sufficiently included in the geographical education special in the literature of the field.

The aim of this study is to draw the attention of geography educators and researchers to geogames, which focus on the value of space and explore the use of different geospatial visualizations in various applications and offer a scientific perspective focused on the phenomenon of urbanization as an academic discipline. In this context, "How geogames can support geographical education?" in line with the research question, some geogames and projects that are most noticeable in the limited literature and related to geography were selected. After the general characteristics of these games were briefly introduced, it was discussed how they can relate to geographical education. 


\section{Methodology}

This review can be considered a general preliminary study that reveals the possible potential of geogames in geography education. The results of this study are limited only to the geogame examples discussed here. In their book' Geogames and Geoplay, Ludografi, created by Ahlqvist \& Schlieder (2018), lists the geogames mentioned in chapters of the book, as well as video and online games. These are (1) Console games, massively multiplayer online games or virtual worlds; (2) Platforms used to create and/or run games; (3) Location-based geogames; (4) Desktop geogames. In this study, this Ludography was taken into account in the selection and classification of geogames, which are thought to be particularly relevant to geographic skills and geography issues. Besides, other special studies which are described as geogames in the literature were included and thus a total of 9 games were studied.

In this review, YouPlaceIt! (Poplin \& Vemuri, 2018) and Geocaching on the Moon (Zhang, 2018) desktop geogames; Neocartographer (Feulner \& Kremer, 2014), Ingress (Tokgöz, 2017) and OriGami (Bartoschek, et al., 2018) location-based mobile geogames are discussed. SimCity (Kim \& Shin, 2016) game, which is listed within console games is also included. Indeed, SimCity can be perceived as a simplified GIS in that it treats various variables such as traffic, population, and economic growth as layered models and presents the results of the interaction of these variables (Gaber, 2007; Minnery \& Searle, 2014 as cited in Kim \& Shin, 2016). Apart from this, according to the literature searches, Project Lily Pad (Tomaszewski, B., Walker, A., Gawlik, E., Lane, C., Williams, P., Orieta, D., ... \& Schwartz, D., 2020), Minecraft-Urban Planning (Andrade, et al., 2020), and FindeVielfalt Simulation (Schaal, et al., 2018) game projects qualified as 'Geogame' and bearing the characteristics of geogames are also included in the sample.

\section{Findings}

\section{Project Lily Pad. (Tomaszewski, et. al., 2020)}

It is a serious game designed specifically for the training of disaster professionals, due to the need to improve disaster resilience and response efforts following the devastation caused by the 2017 Atlantic hurricane season. The game design is aimed to increase disaster resilience through the combination of GIS, spatial thinking, and disaster resilience. The game teaches a four-fold set of skills relevant to spatial thinking and disaster resilience, including reading a map, navigating an environment, coding verbal instructions, and determining best practices in a disaster situation. As a result of the application made with a sample of 10 people consisting of undergraduate and graduate students; there has been a general increase in the participants' confidence in the ability to navigate an unfamiliar area, navigate without a phone or a paper map, translate spoken instructions into visual directions, and find an alternative route or re-route when a road is blocked. In the Lily Pad Project, GIS was used for Dickinson-Texas to develop a sense of place using real-life data. However, by not directly integrating GIS analytic functions such as buffers and layers into the game (such as a handheld map, placement of landmarks, and switching between layers), users without experience 
in using GIS, are also enabled to use different types of spatial information. Other platforms are planned to be developed for the Project Lily Pad, which is currently only available for download from computers, and it is recommended that these game format decisions are made primarily for public use.

\section{YouPlacelt! (Poplin \& Vemuri, 2018)}

YouPlacelt! is an online serious geogame about Dharavi, a low-income neighborhood of Mumbai with about three million residents. The game is an urban planning scenario that focuses on building consensus and negotiation among stakeholders in urban development. Players use critical thinking and GIS tools to analyze and overcome both topographical and economic barriers. The real problems of Dharavi citizens were attempted to represent, and the neighborhood as well in a visually authentic way was to depict at the game scenario. For this, Dharavi's satellite images have been used. Planning and negotiation are at the heart of the game. The game relies heavily on collaboration between players to solve problems with path planning and budgeting. The game has a map interface with familiar GIS features, and chat functionality that allows players to communicate. A two-player game is currently being implemented; A multiplayer game is planned to be implemented in the future.

\section{Minecraft- Urban Planning (Andrade, et. al., 2020)}

Children aged 4-14, living in the Brazilian town of Tirol, participated in the study, where the potential of Minecraft in the participation of children and young people in urban planning was evaluated. Tirol is a small town in Brazil built-in 1859 by Austrian Tyrolean immigrants. It is considered a rural area because it has no internet access and a limited number of computers. In the game, the children put themselves in the shoes of their ancestors who founded the town in which they lived and had the opportunity to completely redesign Tirol. In the study, the values of the children who reconstructed their own town were examined, and how they expressed these, regarding their hometown was also questioned. Therefore, representing scenarios based on heritage values in the game environment in Minecraft; techniques and technologies based on GIS are used to visualize, explore, design, evaluate and negotiate. Children's creativity, problem-solving, selfmanagement, and collaboration skills had to be developed so that the socioeconomic and spatial-temporal issues in the Minecraft environment could be better understood. For this, the Tirolcraft virtual environment was combined with fun quests for exploration and visualization. It was observed in the study that creativity, mapping skills, and spatial thinking improved. As a matter of fact, in applications; it has been observed that children were able to locate their houses; could correlate the map with the real landscape; managed to align the digital, real, and mental mapping; can comprehend basic cartographic principles such as metric proportion, scale, coordinate system, symbols and legends, and their orientation-related skills and knowledge in the fields of architectural history, city planning, and physical geography improved. In addition to this, it is also observed that they have a better 
understanding of architecture (building materials, application, scale, color, typology) and landscape (geomorphology, relief, soil, water resources, green areas, landscape typologies) and they turn Tirol, which has a dispersed settlement, into a collective settlement in their designs.

\section{Geocaching on the Moon (Zhang, 2018).}

The Moon Exploration is a multiplayer online geocaching game based on real scientific data from direct moon exploration, spacecraft, satellites, and observations on Earth. The aim is to make the Moon accessible as the "eighth continent" of the Earth. A user can explore any location on the Moon's surface in the virtual world while roaming the Earth. The game offers a participant convincing first-hand experiences as if they were astronauts exploring the Moon. The game offers a participant convincing first-hand experiences as if they were astronauts exploring the Moon, and is also a mixed reality game. The game also encourages communication and social interactions between players to create a Lunar geocaching community on Earth. The Moon Exploration is designed as a powerful crowdsourcing platform where serious lunar research can be done. Therefore, the target users range from third or fourth-year graduates to professionals and experts. As this game will be across-platform, it can be played on desktop computers, laptops, tablets, or mobile phones. Affordable and portable VR devices are essential components of The Moon Exploration. The Moon Exploration can serve as a sandbox where innovative ideas, designs, and plans can be prototyped, tested, and modified. The game also aims to draw the attention of younger generations to space exploration and STEM learning.

\section{SimCity (Kim \& Shin, 2016)}

Researchers examined the pedagogical potential of the SimCity simulation game in an urban geography lesson. University students have used SimCity to build their own cities and have applied a wide variety of urban theories to support their urban structures. In addition, the students critically evaluated the logic and functioning of the SimCity simulation by comparing it with real-world contexts and principles of urban geography. The students stated that the SimCity event provided them with opportunities to develop their geographic creativity and as a result, diverse, unique, and interesting cities were created. The findings show that the use of SimCity can be an effective tool for geography education.

\section{Neocartographer (Feulner \& Kremer, 2014)}

Neocartographer, one of the location-based geogames, is one of a series of games called Geogames developed at Bamberg University since 2004. The main purpose of this geogame project developed for high school students is to understand the spatial decisions of the players. In the game, a class is divided into several teams ranging from two to five members. Teams compete with each other in parallel game sessions. The aim of the players is to move around a real playground - outside and occupy virtual spaces. Players must find specific geographic locations on the field to occupy these areas; after solving a game task, these areas are marked with the color 
of a particular team and are no longer accessible by the other team. Each team can see the areas that the opposing team is currently occupying on their mobile device screens, and so they need to make strategic decisions. It is recommended to link it under a central geography question or a central topic, with all the content of the game. Multiple task combinations are also possible in one place. These spatial tasks can be information-based, verbally performed as an exploratory task, or perform a geographic data collection function. The game is basically played outside the classroom - in an open space; however, the spatial decisions of the players, the geographic data they collect and their roles can be discussed later in the classroom. Students' own data collected during Geogame Neocartographer are used to make their own personal maps; learning subject can be dealt with in these maps. With a high degree of self-control and student-centered structure, competencies such as subject-specific knowledge acquisition, communication, and negotiation practices (in spatial situations), or team-building strategies can also be developed. In addition, students gain a new functional knowledge of operating mobile devices and experience the range of media in an improved context. The results of the study show that geogames can be used in educational scenarios for many purposes. Motivational research results show that games simultaneously develop many competencies and provide students with high motivation. Essentially, the game encourages students to visit places they have never been to in their daily routine and to observe in a way they wouldn't otherwise. This increases spatial thinking skills.

\section{FindeVielfalt Simulation (FVS) (Schaal, et. al., 2018)}

The game takes place in South-West German traditional gardens combined with a virtual orchard in the story. The main character must explore and operate a traditional orchard that is the legacy of his ancestors. Players use their smartphones for GPS-based navigation and explore real places in nature. When they reach real places marked virtually, they automatically receive a new story sequence and a new task to solve. Players deal with problems or dilemmas, observe animals and plants, and transfer their solutions to the smartphone using tools such as integrated cameras, recording, and messaging. Some tasks require answers to multiple-choice questions; in others, the images need to be matched with terms or arranged according to a timeline. After each mission, players manage a virtual orchard in a simulation. They plant or remove different fruit trees to explore their impact on both biodiversity and economic outcome. Data for the game app was collected from 206 German grammar school students who played FVS geogame during an extracurricular event in a traditional orchard in Southwest Germany in the summer of 2015 and 2016. During the game sessions lasting 1,5-2 hours, the average age was 14 in groups of 2-3 players. Geogames also provides convenient opportunities for outdoor environmental education as it is mobile, location-aware and location-based games. The geogame FindeVielfalt Simulation is a location-based game developed in the BioDiv2Go project, providing sensory experiences, exploring local biodiversity, and enhancing biodiversity knowledge and attitudes towards nature. Geogame FVS has a high potential to both improve knowledge on biodiversity, and regardless of 
personal preconditions, develop attitudes towards nature, even in adolescents.

\section{Ingress (Tokgöz, 2017)}

It is a location-based mobile game introduced by Niantic Lab to Android users in December 2013 and IOS users in July 2014. It is a hybrid reality application that combines physical space and digital information with its motto: "The world around you is not what it seems!" In Ingress, there are 'Resistance' and 'Enlightened' teams struggling with each other. In the beginning, the story of the game is told and the player is asked to choose a side. According to the story, scientists at CERN discovered the Exotic substance (XM - Exotic Matter) in their studies to discover the "Higgs Boson". XM's spread to the world through physical space elements called "portals". The game's portals, structured on Google Maps, are directly the real elements of the city, such as monuments, squares, and buildings. For example, the Kamondo stairs in Eminönü, Istanbul is a portal in the game, and in order to capture it, the players named 'Agent' must go to where this portal is. While the Enlightened people, represented by the green color, want to take XM and use it to evolve humanity into a better state; on the other hand, the Resisters, represented in blue, are trying to capture this substance in order to protect humanity since the power of mind-reading it provided, can capture humanity. In this strategy game, the goal is to capture the portals and connect them to gain the space in between. Despite the simplicity of Ingress's interface, which resembles a simple sketch, the fact that it is played together with real people in real space creates the illusion of being in a mentally fantastic world in daily life. The Intel map, which is a representation of the city's map, used by Ingress players to access portals, improves players' ability to navigate and use maps. While Ingress encourages the player to go out into the street and discover new places, making the space memorable through its interface and narrative.

\section{OriGami (Bartoschek, et. al., 2018)}

OriGami (Orientation Gaming) is a mobile game designed to help school-age children develop their spatial thinking skills (it is also a geogame played on a desktop computer; see Ola Ahlqvist and Christoph Schlieder (2018) 's Ludography, p.238). OriGami was created specifically to teach concepts such as georeferencing, symbology basics, orienting. The game especially encourages players to find routes. The game is quite successful, given the importance of aligning, orienting, and visualizing one's own position according to points of interest to navigate a disaster scenario (Tomaszewski, et al., 2020). OriGami can be played single user or multiuser; an application for browsers or tablets. The application is based on ESRI JavaScript API and IONIC Framework mobile application development. Depending on the platform, it can be used in mobile or stationary with GPS. The game can be played, for example, in the real environment (providing real experiences for the player) or in fixed classroom mode, depending on the settings chosen by the teacher. The routes in the navigation task and the task at the destination can be set by the teacher; route instructions can be provided and edited by the teacher or game 
leader. The user receives instant feedback for their actions via a smiley (Emoji). Feedback and tips allow the user to find and navigate reference points on the map and in the real world. In general, playing digital games improves the social skills of the user. Students are expected to work better as a team and gain experience in using geospatial technologies. ICT (Information and Communication Technologies) skills are applied by playing digital games. Many spatial competencies are studied theoretically at school. Geogames allow users to experience many of these theoretical concepts in the real world. Like experiencing map alignment and orientation in a mission to find a targeted path, or experiencing the concept of a coordinate system and the cardinal points in the real world.

\section{Result and Discussion}

In this study, the innovative geogames game that can contribute to the development of GIS, spatial thinking, and geographic inquiry skills was introduced with examples from the literature, and the attention of the geography educators and researchers have been tried to attracted to this game-based teaching technology. For this, YouPlaceIt! Geocaching on the moon, Neocartographer, OriGami, SimCity, Project Lily Pad, Minecraft-Urban Planning, Geogame FVS and Ingress geogame applications and projects are briefly introduced in the findings section.

In the literature review, it was found that most geogame applications have the features of 'serious game' and/or 'pervasive game' and/or' location-based mobile game' and/or 'desktop game'. This situation, which can be quite complicated for a reader or educator who is not very familiar with the digital game world, is actually due to the wide spectrum of the digital game industry. In order to better understand the place of Geogame among these games, within the scope of this study, a simple explanation can be made as follows: The main feature that distinguishes serious games from other digital games is that the purpose of education is in the first place and the field expert is used in game design. Pervasive games, on the other hand, turn urban spaces into playgrounds with augmented reality technologies on mobile devices and embed the game into the daily life of the player. Geogame differs from other serious games by basically using GIS technology, focusing on solving a spatial problem together with its stakeholders.

Considering the general subject areas of the games discussed in the study, Project Lily Pad disaster resistance; YouPlaceIt! Minecraft-Urban Planning and SimCity city planning; Geocaching on the Moon space geography (lunar geography); Geogame FVS is about biodiversity. It has been stated that in the Neocartographer, all kinds of geography issues can be dealt with in the axis of map-based spatial thinking skill. OriGami focuses directly on the training of spatial thinking skills. While Ingress enables its users to explore the city with its pervasive game structure, it also contributes to the development of the players' observation and navigation skills.

When we look at the player profiles, it can be said that the games can be played in almost every age group. Besides, Ingress, Project Lily Pad, SimCity, YouPlaceIt! and Geocaching on the Moon can be said to have a high potential in informal learning. The social networking platform owned by Ingress and Geocaching on the Moon is an important advantage in terms of the continuous renewal and spread of these games. 
It was observed that the application samples of the geogames presented in the findings were small. This is because most of the geogames introduced here are still in the prototype stage; requiring field experts and technical staff to work together during its development as in serious games; some require advanced technology such as pervasive games and most importantly, geogames may require serious time, technical equipment, effort, and budget. Although this situation seems to be a problem in the development of this geogame instructional technology (Andrade et al., 2020), it is seen that pervasive and serious games (Solinska-Nowak, et al., 2018) find a wide place in various fields. This result can be reached from even the number of Pokemon Go players alone (Freese, 2016). In addition, it is a known fact that the use of augmented reality technologies in daily life and mobile devices has become widespread. The main problem here is the scarcity of evidence of the learning outcomes of these geogame applications (Andrade et al., 2020; Baker, et al., 2015; Carbonell Carrera, et al., 2018; Schneider, Schaal, \& Schlieder, 2017); when considering especially in the context of this study, it is the lack of proven data on the acquisition of spatial thinking and geographic skills.

This situation raises the following questions for researchers and geography educators: Educational subject-based game design and implementation; how to use the necessary technology; how to provide widespread and cheap access to these games; how to approach games in pedagogical terms, which games to choose, and teacher training; how games can be updated with feedback, and how necessary cooperation and promotion can be provided; and it raises the questions of how to collect concrete data on learning outcomes of games, and it brings up new research areas.

Seidel et al. (2020) mentioned that all students may not be able to purchase or access digital games and suggested that these games should be implemented in the classroom under the supervision of a student who is an expert in the game. They stated that if there are no experienced students in the classroom, it is possible to use Let's Play videos on platforms such as YouTube where these games are presented on the Internet. Seidel et al., (2020) stated that teachers should be aware of the possibilities and challenges of new media, and teachers' media pedagogical support or their pedagogical specialization in media are also important elements in using the learning potential of computer games.

The development of the possibilities of playing geogames, especially on mobile devices, is another matter. Schneider, et al. (2017) stated that geogames are location-based games played outdoors and support a wide variety of learning experiences in areas such as cultural heritage and biodiversity, but little is known about how different aspects of location-based gameplay interact temporally. In general, in all game types, the aim is to transfer the game to location-based mobile applications. Thus, the game will be able to reach a larger audience anytime, anywhere. As a matter of fact, Neocartographer, Ingress, OriGami, and Geogame FVS, among the geogames presented in the findings, are mobile, location-aware, and location-based games for devices such as smartphones and tablets. Geocaching on the moon geogame can be played on mobile devices as well as having a pervasive game feature. Project Lily Pad practitioners stated that they intend to move the game 
to mobile platforms. This is especially important for educators in terms of widespread and less costly implementation.

The rapid proliferation of digital mobile devices among teenagers requires teachers to think about how to integrate this media into their didactic concepts, rather than ignore it. Mobile devices have become an integral part of our daily routine, offer many possibilities for their use in geography teaching: Since its technological functions and Apps such as GPS, compass, altimeter, (digital) maps, video and photo camera, dictaphone, and sound level meter offer interesting alternatives to most traditional geographic tools, they are particularly applicable for excursions and fieldwork (Feulner \& Kremer, 2014). These devices can be used for location-based learning as they provide the link between a geographic location and the curriculum referring to that location. In addition, considering the motivational potentials of digital game-based learning, there is a great possibility for sustainable learning (Feulner \& Kremer, 2014).

It was emphasized that spatial thinking skills developed in the games, especially in OriGami, Project Lily Pad, and Minecraft-Urban Planning geogames. Bartoschek et al. (2020) claim that many geogames are built on orientation and map comprehension capabilities, in line with contemporary educational goals that promote spatial literacy. Geographical inquiry skill is notably is at the forefront of Project Lily Pad and Minecraft-Urban Planning, SimCity, and YouPlaceIt! Considering the general features of the games included in the study, it is seen that geogames are very related to geography science in which spatial technology and geographic inquiry are made.

When other serious games and geogames in the literature on increasing disaster resistance are evaluated; Hazagora (Mossoux, et al., 2016) describes how disasters affect the vulnerable population; it aims to raise people's awareness of the factors that lead to disasters and existing strategies to mitigate their effects. The target groups of the game are secondary school students, citizens, scientists, and stakeholders involved in risk management activities. Code Red: Triage (van der Spek, Wouters, \& van Oostendorp, 2011) focuses on individual training in crisis management. According to Tomaszewski, et al. (2020), OriGami clearly shows routefinding and landmark-based navigation while YouPlaceIt! gives a sense of place. The Lily Pad Project is the first attempt to integrate spatial thinking, disaster resistance, and GIS into serious games. Which spatial thinking skills are related to disaster resilience and how these can be helped by GIS are searched, and it is a preliminary study on whether serious games can be effective as educational tools to develop spatial thinking (Tomaszewski, et al., 2020).

YouPlaceIt! Can we create an online serious geogame that will enable negotiations? Could such a game bring the people of Dharavi and relevant stakeholders together? It involves developing a prototype that allows discussions on planned activities in Dharavi or a selected neighborhood within the framework of these questions. Other achievements in the game, which aim to create an online, digital environment based on communication, language use, and consensus, are the concrete experience of language-negotiation and power relations. Therefore, this game can be connected with the political geography area. 
According to Kim \& Shin (2016), in the literature, SimCity was adopted as a pedagogical tool in practices such as urban geography, hydrology, planning training, and environmental education. However, they noted that Geographers, despite its close connection with geographic content and skills, do not systematically examine the benefits of SimCity for teaching Geography. SimCity environments attract student attention; It is particularly suitable for geography education as it develops geographical understanding and critical thinking skills and enhances geographic creativity by giving them autonomy to build their own cities. SimCity players understand that the city is a system, define the problem, and try to reach a reasonable solution through critical analysis (Kim \& Shin, 2016). In this context, it can be concluded that geogames encourage critical thinking, problem-solving and creative thinking in parallel with the geographic inquiry.

Minecraft, in which real spatial contexts are modeled by its players, represents an example of a geogame capable of visualizing the real world and its geographic context (Andrade, et al., 2020). One of the most striking results in terms of geographic skills in the game is the development of time perception, perception of change and continuity, and map skills, consequently spatial thinking. Similar learning outcomes also apply to the YouPlaceIt! Mathews \& Holden (2018) says that mobile technologies offer new ways of knowing where we are, from emphasizing our position in time and space to defining and interpreting our environment, to developing new sociocultural and identity-based awareness modes.

Geogames can provide opportunities for students to tell their own local stories and participate in discussions and actions that affect the future of local communities. In addition, geogames can be used to highlight both the cultural and ecological aspects of local places. In this context, place-based education may be an appropriate approach for geogames applications (Mathews \& Holden, 2018).

Cömert (2020) created Minecraft Edu activities and lesson plans for secondary school students in the fields of science, mathematics, social studies, and foreign language education: The world of environmental pollution with MinecraftEdu, The world of treasure hunt with MinecraftEdu, The airfield world with MinecraftEdu, The gcd-lcm (Ebob-Ekok) world with MinecraftEdu, The world of rural to urban migration with MinecraftEdu, and The world of simple electrical circuit and lighting system with MinecraftEdu. Although Cömert (2020)'s Minecraft Edu activities are not built on real geospatial data, they show that geographic skills can be gained direct or indirectly in a digital game design made with MinecraftEdu, which is easy to access and use for everyone.

Geogame FVS can be particularly associated with biodiversity, vegetation geography, and environmental education. With an appropriate approach, it can contribute to the development of navigation skills as well as fieldwork and observation skills in the geography course. The game aims to increase biological diversity and earn money. Therefore, Geogame FVS can be an innovative teaching strategy in sustainable development and sustainable environmental education, if properly implemented, as students will contemplate the balancing of economic and environmental interests. 
Geocaching on the Moon geogame is based on the rules of the geocaching game. Therefore, the geogame has the potential to benefit from the global social network and player base of geocaching. The Moon Exploration is designed as a powerful crowdsourcing platform where serious moon research can be done, and this platform is also planned to function in a way as an R\&D (research and development). In the game, children and young people are encouraged to explore space and learn STEM. In addition to these advantages, there are opportunities to compare the Earth and Moon surface structure, to learn GPS and geographic coordinates in the game. In addition to physical geography issues such as earth sciences, rocks, geomorphological-geological processes, natural resources, the gameplay actions such as building colonies on the lunar surface through collaborative working, can also allow players to experience resource management and planning.

The mixed reality structure, sense of exploration, and collaborative nature of the game can reflect positively on the motivation of the player. Similarly, the ingrained game culture of the Ingress can be a valuable resource for geography education. Being constantly in the game, which strongly affects the motivation of the players, and exploration of the city can be especially beneficial for learning the subjects of local history, cultural geography, tourism geography, and urban geography in an enjoyable way.

Informal learning potential is high in both Geocaching on the Moon and Ingress geogames. In addition, it is highly probable that geographic skills such as time perception, fieldwork, observation, perception of change-continuity can develop in these games. Geography educators can design appropriate activities for these games; the problem of accessing games also could be solved to a great extent via mobile devices. As these games evolve and spread, many educational activities and new learning strategies are likely to emerge as we envision here.

\section{Suggestions}

When the results of the research are evaluated geogames can be an effective and popular tool in both informal learning and formal learning environments especially at local and global problems' solutions that required geography inquiry skill and spatial literacy. However, it seems that the main problems, very briefly, are that schools may not have sufficient technical infrastructure for these digital games, the need for expert teachers on this subject, and the lack of existing geogame and projects in geography education.

In this study, which presents an overview of geogames in the context of geography education, another point of note is that serious games and pervasive games can also have important benefits in terms of geography education. In this regard, it is recommended that the learning outcomes and potentials in the educational applications of geogames, serious and pervasive games be supported by concrete evidence obtained through a mixed research approach. 


\section{References}

Ahlqvist, O. \& Schlieder, C. (2018). Geogames and Geoplay. Cham, Switzerland: Springer International Publishing

Andrade, B. D., Poplin, A., \& Sena, Í. S. D. (2020). Minecraft as a Tool for Engaging Children in Urban Planning: A Case Study in Tirol Town, Brazil. ISPRS International Journal of Geo-Information, 9(3), 170. doi:10.3390/ijgi9030170

Artvinli, E. (2020). Coğrafi Sorgulama Becerisi. Ç. Öztürk Demirbaş (Ed.), Coğrafi beceriler içinde (1. baskl. ss. 81-140). Ankara: Nobel.

Artvinli, E. \& Kaya, N. (2010). 1992 International charter on geographical education and its reflections in Turkey. Marmara Coğrafya Dergisi, 22, 93-127. Retrieved from https://dergipark.org.tr/en/pub/marucog/issue/469/3792

Avouris, N. M., \& Yiannoutsou, N. (2012). A review of mobile location-based games for learning across physical and virtual spaces. Journal of Universal Computer Science (J. UCS), 18(15), 2120-2142. Retrieved from http://www.jucs.org/jucs_18_15/ a_review_of_mobile/jucs_18_15_2120_2142_avouris.pdf

Baker, T. R., Battersby, S., Bednarz, S. W., Bodzin, A. M., Kolvoord, B., Moore, S., ... \& Uttal, D. (2015). A research agenda for geospatial technologies and learning. Journal of Geography, 114(3), 118-130. doi: 10.1080/00221341.2014.950684

Barab, S., Thomas, M., Dodge, T., Carteaux, R., \& Tüzün, H. (2005). Making learning fun: Quest Atlantis, a game without guns. Educational technology research and development, 53(1), 86-107. doi:10.1007/BF02504859

Barbosa, A. F., Pereira, P. N., Dias, J. A., \& Silva, F. G. (2014). A new methodology of design and development of serious games. International Journal of Computer Games Technology, 2014, 1-9. doi:10.1155/2014/817167

Bartoschek, T., Schwering, A., Li, R., Münzer, S., \& Carlos, V. (2018). OriGami: A Mobile Geogame for Spatial Literacy. In O. Ahlqvist \& C. Schlieder (Eds.), Geogames and Geoplay: Game-Based Approaches to the Analysis of Geo-Information (1st ed., pp. 3763). Cham, Switzerland: Springer International Publishing.

Bilgiç, H. G., Duman, D., \& Seferoğlu, S. S. (2011, Şubat). The characteristics of digital natives' and their effects of on the design of online environments. Akademik Bilişim, 2(4), 1-7. Malatya.

Carbonell Carrera, C., Saorín, J. L., \& Hess Medler, S. (2018). Pokémon GO and improvement in spatial orientation skills. Journal of Geography, 117(6), 245-253. doi:10.1080/00221341.2018.1470663

Cömert, A. (2020). Student opinions for problem solving activities designed and applied with digital game based learning method (Master's thesis). Retrieved from The Higher Education Council National Thesis Center. (Thesis No.620265)

Feulner, B. \& Kremer, D. (2014). Using geogames to foster spatial thinking. In R. Vogler, A. Car, J. Strobl \& G. Griesebner (Eds.), GI_Forum 2014. Geospatial Innovation for Society (pp. 344-347). Berlin. doi:10.1553/giscience2014s344

Frasca, G. (2001). Rethinking agency and immersion: video games as a means of consciousness-raising. Digital Creativity, 12(3), 167-174. doi:10.1076/digc.12.3.167. 3225 
Freese, P. (2016). Pokémon go: Ist der Hype beendet? [Pokémon go: Is the hype finished?] Mein MMO- Das Magazin für Online Spiele. Retrieved from http://meinmmo.de/pokemon-go-ist-der-hype-beendet/

Kim, M. \& Shin, J. (2016). The Pedagogical Benefits of SimCity in Urban Geography Education, Journal of Geography, 115 (2), 39-50, doi: 10.1080/00221341.2015. 1061585

Mathews, J. \& Holden, C. (2018). The Design and Play of Geogames as Place-Based Education. In O. Ahlqvist \& C. Schlieder (Eds.), Geogames and Geoplay: Game-Based Approaches to the Analysis of Geo-Information (1st ed., pp. 161-177). Cham, Switzerland: Springer International Publishing.

Ministry of National Education (MoNE) (2018). High School Geography Curriculum. Ankara. Retrieved from https://mufredat.meb.gov.tr/ProgramDetay.aspx?PID=336

Mossoux, S., Delcamp, A., Poppe, S., Michellier, C., Canters, F., Kervyn, M. (2016). Hazagora: Will you survive the next disaster?-A serious game to raise awareness about geohazards and disaster risk reduction. Nat. Hazards Earth Syst. Sci. 16, 135-147. doi: 10.5194/nhess-16-135-2016,

National Research Council (NRC), (2006). Learning to Think Spatially: GIS as a Support System in the K-12 Curriculum. Washington, DC: The National Academies Press

Nguyen, T. (2016). Serious games. Significance. 13(6), 14-19. doi:10.1111/j.17409713.2016.00978.x

Nicklas, D., Pfisterer, C., \& Mitschang, B. (2001). Towards location-based games. In Proceedings of the international conference on applications and development of computer games in the 21st century: ADCOG (Vol. 21, pp. 61-67).

Polat, E. \& Varol, A. (2012). Educational computer games effect of academic success: Example of social sciences course. Akademik Bilişim. Retrieved from https://ab.org.tr/ab12/bildiri/166.pdf

Poplin, A., Kerkhove, T., Reasoner, M., Roy, A., \& N. Brown (2018). Serious GeoGames for civic engagement in urban planning: discussion based on four game prototypes. In: Yamu, C., Poplin, A., Devisch, O. and G. de Roo (eds) The Virtual And The Real: Perspectives, Practices and Applications For The Built Environment, p. 189 - 213, Routledge, Taylor \& Francis Group, London and New York.

Poplin, A. \& Vemuri, K. (2018). Spatial Game for Negotiations and Consensus Building in Urban Planning: YouPlaceIt! In O. Ahlqvist \& C. Schlieder (Eds.), Geogames and Geoplay: Game-Based Approaches to the Analysis of Geo-Information (1st ed., pp. 6391). Cham, Switzerland: Springer International Publishing.

Prensky, M. (2001). Digital natives, digital immigrants part 1. On the horizon, 9(5), 1-6. doi:10.1108/10748120110424816

Ratan, R. A. \& Ritterfeld, U. (2009). Classifying serious games. In U. Ritterfeld, M. Cody, \& P. Vorderer (Eds.), Serious Games: Mechanisms and Effects (pp. 32-46). Routledge. 1022

Salen, K., \& Zimmerman, E. (2003) Rules of Play. MIT Press

Schaal, S., Otto, S., Schaal, S., \& Lude, A. (2018) Game-related enjoyment or personal prerequisites - which is the crucial factor when using geogames to encourage adolescents to value local biodiversity, International Journal of Science Education, Part B, 8(3), 213-226, doi: 10.1080/21548455.2018.1441571 
Schlieder, C., Kiefer, P., \& Matyas, S. (2006). Geogames: Designing location-based games from classic board games. IEEE Intelligent Systems, 21(5), 40-46. doi: 10.1109/MIS.2006.93

Schneider, J., Schaal, S., \& Schlieder, C. (2017, September). Geogames in education for sustainable development: Transferring a simulation game in outdoor settings. In 2017 9th International Conference on Virtual Worlds and Games for Serious Applications (VSGames), 79-86, Athens, Greece. doi: 10.1109/VS-GAMES.2017.8056574.

Seidel, S., Bettinger, P., \& Budke, A. (2020). Representations and concepts of borders in digital strategy games and their potential for political education in geography teaching. Education Sciences, 10(1), 10. doi: 10.3390/educsci10010010

Solinska-Nowak, A., Magnuszewski, P., Curl, M., French, A., Keating, A., Mochizuki, J., ... \& Jarzabek, L. (2018). An overview of serious games for disaster risk managementProspects and limitations for informing actions to arrest increasing risk. International journal of disaster risk reduction, 31, 1013-1029. doi.10.1016/j.ijdrr.2018.09.001

Spallazzo, D. \& Mariani, I. (2018). Location-based mobile games: Design perspectives. Springer International Publishing

Stenros, J., Montola, M., \& Mäyrä, F. (2007, November). Pervasive games in ludic society. In Proceedings of the 2007 conference on Future Play (pp. 30-37).doi: 10.1145/1328202.1328209

Tokgöz, C. (2017). Location-based mobile games and sense of place: An ethnographic study on Ingress. Ankara Üniversitesi İlef Dergisi, 4 (2), 7-36. doi: 10.24955/ilef.357094 Retrieved from https://dergipark.org.tr/en/pub/ilef/issue/32569/357094

Tomaszewski, B., Walker, A., Gawlik, E., Lane, C., Williams, S., Orieta, D., ... \& Schwartz, D. (2020). Supporting Disaster Resilience Spatial Thinking with Serious GeoGames: Project Lily Pad. ISPRS International Journal of Geo-Information, 9(6), 405. doi:10.3390/ijgi9060405

Tüzün, H., Yılmaz-Soylu, M., Karakuş, T., Inal, Y., \& Kızılkaya, G. (2009). The effects of computer games on primary school students' achievement and motivation in geography learning. Computers \& education, 52(1), 68-77. doi.10.1016/j.compedu. 2008.06.008

Ünlü, M. \& Yıldırım, S. (2017). A geographical skill suggestion to geography teaching curriculum: Spatial thinking skill. Marmara Coğrafya Dergisi, 35, 13-20. doi: $10.14781 / \operatorname{mcd} .291018$

Wikipedia (2021, 20 January). Pervasive game. https://en.wikipedia.org/wiki/Pervasive _game

Van der Spek, E. D., Wouters, P., \& van Oostendorp, H. (2011). Code red: triage or cognitionbased design rules enhancing decisionmaking training in a game environment. British Journal of Educational Technology, 42(3), 441-455 doi.10.1111/j.1467-8535.2009. 01021.x

Virvou, M., Katsionis, G., \& Manos, K. (2005). Combining software games with education: Evaluation of its educational effectiveness. Journal of Educational Technology \& Society, 8(2), 54-65.

Yamu, C., Poplin, A., Devisch, O., \& De Roo, G. (2017).The Virtual and the Real in Planning and Urban. Design: Perspectives, Practices and Applications; Routledge: Abingdon, UK, 2017. 
Zhang, C. (2018). Geocaching on the Moon. In O. Ahlqvist \& C. Schlieder (Eds.), Geogames and Geoplay: Game-Based Approaches to the Analysis of Geo-Information (1st ed., pp. 209-233). Cham, Switzerland: Springer International Publishing.

\section{Biographical Statement}

Rukiye ADANALI works in the Department of Social Studies Education at Muğla Sitkı Koçman University. Her research interests include geography education, social studies education, digital game-based learning, problem-based learning, and teacher education.. 